\title{
ESPACIALIZAÇÃO DA PRECIPITAÇÃO PLUVIOMÉTRICA NA REGIÃO METROPOLITANA DE CAMPINAS NO PERÍODO DE 1976 A 2012
}

\author{
Deborah Fernanda Santana Gimenez ${ }^{(a)}$, Adriana Fantinati Conceição ${ }^{(b)}$, Denivaldo Ferreira de \\ Souza $^{(\mathrm{c})}$, Jonas Teixeira Nery ${ }^{(\mathrm{d})}$ \\ (a)Programa de Pós-graduação em Geografia da Universidade Estadual de Campinas - UNICAMP. \\ (deborahsntna@gmail.com). \\ (b)Programa de Pós-graduação em Geografia da Universidade Estadual de Campinas - UNICAMP. \\ (adriana.fantinati.c@gmail.com). \\ (c)Programa de Pós-graduação em Geografia da Universidade Estadual de Campinas - UNICAMP. \\ (deny1609@gmail.com). \\ (d)Livre Docente. Universidade Estadual Paulista “Júlio de Mesquita Filho” - UNESP. (jonas@ ourinhos.unesp.br).
}

\section{Eixo: GEOTECNOLOGIAS E MODELAGEM ESPACIAL EM GEOGRAFIA FÍSICA}

\begin{abstract}
Resumo
O objetivo deste trabalho foi analisar a distribuição espacial e temporal da precipitação pluviométrica da Região Metropolitana de Campinas (RMC), estado de São Paulo. Foram adquiridos dados de chuva disponíveis no site HidroWeb da Agência Nacional das Águas (ANA), referentes ao período de 1976 a 2012. O preenchimento dos dados faltantes foi realizado por meio da técnica das Redes Neurais Artificiais (RNA's). Após o preenchimento dos dados, foram calculadas as médias anuais de precipitação pluvial do período e o total de precipitação de cada ano do período de estudo. Os resultados indicaram que a precipitação pluvial do período oscila entre 1.343 e $1.640 \mathrm{~mm}$. Em relação aos totais anuais, percebeu-se a influência da atuação do El Niño, destacando-se o ano de 1982/83 como o ano com maiores totais.
\end{abstract}

Palavras chave: geoprocessamento, interpolação espacial, krigagem

\section{Introdução}

O estudo da precipitação pluviométrica e sua distribuição espacial constituem uma informação importante para o monitoramento e planejamento de cidades, produção agrícola, atividades de mineração e conservação do meio ambiente (SILVA et al. 2011b., MORAES et al. 2013).

O desenvolvimento de mapas a partir dos quais a pluviosidade possa ser analisada espacialmente, permite ao pesquisador investigar sua relação com diferentes variáveis ambientais (MELLO, 2012), tais como o efeito topográfico estudado por Souza et al (2015) na bacia do Riacho do Saco, no sertão Pernambucano onde identificaram os maiores valores pluviométricos associados ás maiores elevações da bacia e os menores valores próximos à depressão sertaneja, sendo o estudo da relação relevo-precipitação importante para auxiliar na gestão das áreas de risco e planejamento agrícola principalmente no semiárido nordestino. 
Para o monitoramento da precipitação pluviométrica em escala regional é necessária uma alta densidade de pluviômetros bem distribuídos espacialmente, elevando o valor a ser investido na pesquisa (ADAMS et al. 2009), além disso, as estações pluviométricas realizam medições apenas pontuais, não representando áreas extensas, sendo alguns dos problemas encontrados durante as pesquisas: a baixa densidade de estações amostrais, as séries descontínuas de dados e a duração insuficiente das séries disponíveis para se obter tendências climatológicas.

Com o intuito de solucionar estes problemas, diferentes métodos são utilizados para preencher espacialmente essas áreas, como os métodos de interpolação. Estudos comparando métodos de interpolação foram realizados por Silva et al. (2011a), que avaliaram a interpolação pelo Inverso da Potência da Distância (IPD) e por krigagem (KR) para a espacialização da precipitação mensal no estado do Espírito Santo. O método da krigagem apresentou resultados satisfatórios, sendo eficiente para a interpolação espacial da precipitação mensal no Espírito Santo.

A precipitação pluvial está diretamente relacionada à economia, meio ambiente e sociedade, sua espacialização fornece informações importantes para elaboração de projetos de conservação e proteção do solo, áreas com risco de inundação, ciclos de cultivo agrícola entre outras temáticas. Diante do exposto o presente trabalho tem por objetivo analisar a precipitação pluviométrica e sua distribuição espacial na Região Metropolitana de Campinas, estado de São Paulo, entre os anos de 1976 a 2012, com o intuito de identificar os padrões predominantes de distribuição pluvial nos municípios da RMC no período de 37 anos.

\section{Metodologia}

A área de estudo é a Região Metropolitana de Campinas (RMC), estado de São Paulo, que ocupa uma área de $3.647 \mathrm{~km}^{2}$ (Figura 1). A paisagem da RMC passou por várias transformações decorrentes de diferentes ciclos econômicos. Originalmente a região era formada pela vegetação de mata atlântica e cerrado, sendo modificada em decorrência de diferentes ciclos de intensificação agrícola e urbana. Atualmente, as áreas urbanas da RMC concentram a maior parte da população, ocorrendo o fenômeno de conturbação entre algumas cidades (EMBRAPA, 2016). A população da RMC, de acordo com o censo IBGE (2010), é de 2.798.477 habitantes, a $9^{\mathrm{a}}$ maior do país. 

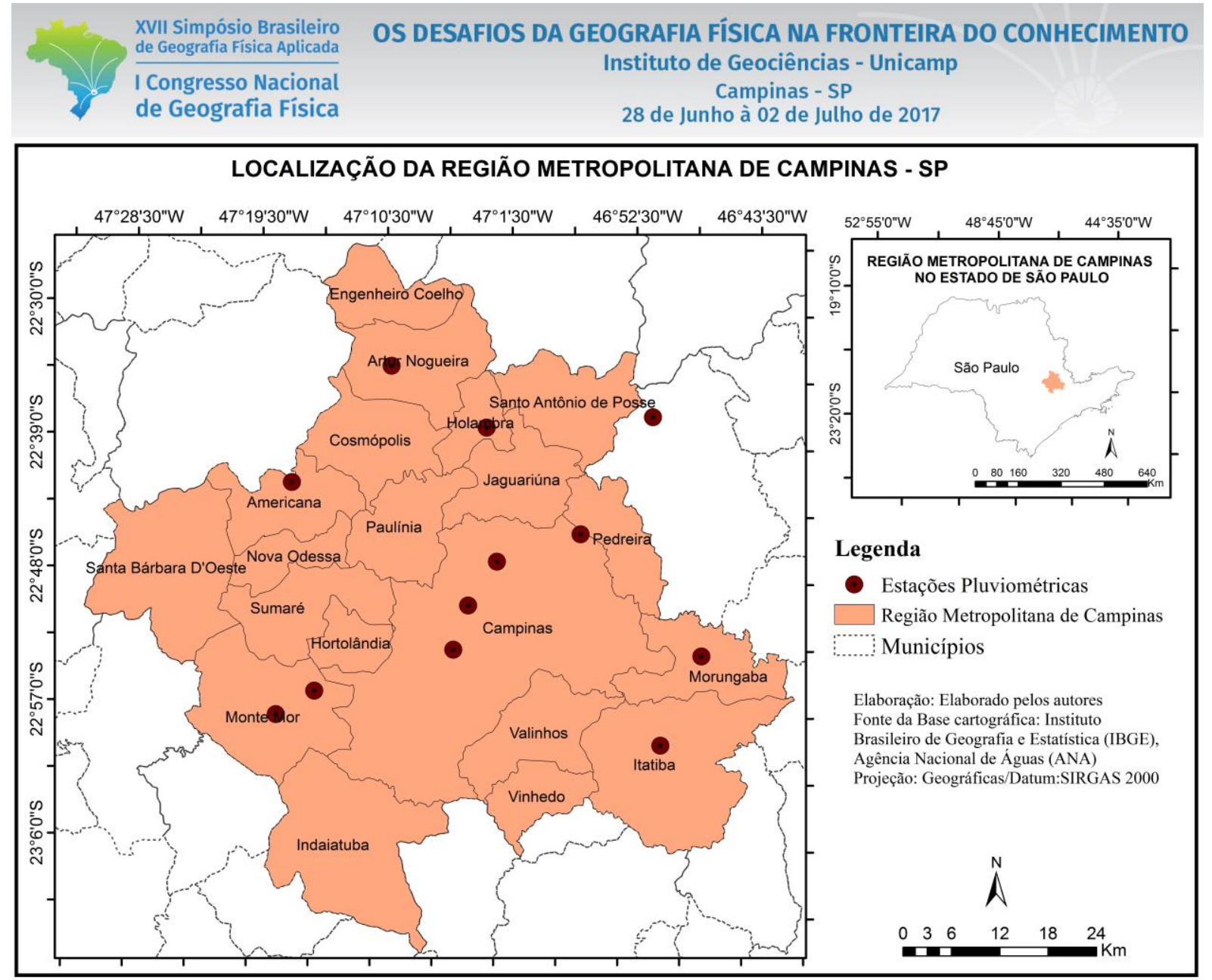

Figura 1 - Localização da área de estudo e distribuição das estações pluviométricas utilizadas na pesquisa.

Para a análise do total de chuva e sua distribuição espacial na RMC, foram obtidos dados diários de precipitação pluvial de 12 séries pluviométricas por meio do sistema HidroWeb, da Agência Nacional de Águas (ANA).Os dados foram organizados em planilha eletrônica, e a qualidade dos mesmos foi verificada e foi possível definir o período de estudo em comum de 37 anos (1976 a 2012).

A organização dos dados possibilitou a observação dos dias com dados faltantes. Estes foram corrigidos por meio da técnica das Redes Neurais Artificiais (RNA's) perceptron multicamadas, calculada em ambiente estatístico R, utilizando-se a sub-rotina prefann (Precipitation Forescating with Artificial Neural Network and others) desenvolvida por Povoa (2015). Teegavarapu e Chandramouli (2005) afirmam que o uso desta técnica tem apresentado resultados satisfatórios na estimativa de dados faltantes de precipitação pluvial. As Redes Neurais Artificiais são técnicas computacionais inspiradas na estrutura neural dos organismos vivos que adquirem conhecimento através da experiência, da mesma forma que o cérebro (HAYKIN, 2008).

No caso das RNA's perceptron multi-camadas, tem-se a camada de entrada, camadas "escondidas" e a camada de saída. Na camada de entrada são apresentadas a série a ser corrigida e as 


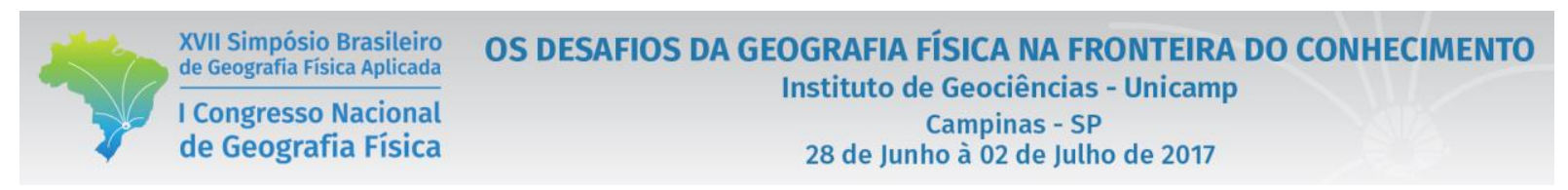

séries de referência, contendo os dados do dia, mês, ano e os dados de precipitação diária correspondentes. Nas camadas "escondidas", a aprendizagem sobre os padrões de chuva é realizada. Nestas, a sub-rotina realiza cálculos, estipula pesos e a partir do aprendizado estima o valor faltante. A camada de saída consiste no resultado final do processamento, nela é apresentada a série com os dados faltantes preenchidos. O esquema abaixo (Figura 2) representa o processo. $\mathrm{O}$ algoritmo utilizado nas camadas intermediárias ou "escondidas" não é conhecido pelo usuário final da sub-rotina R.

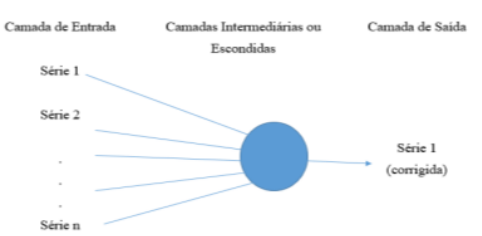

Figura 2 - Estrutura de uma rede neural artificial perceptron multicamada.

Fonte: HAYKIN (2008)

Após o preenchimento dos dados diários em ambiente $\mathrm{R}$, estes foram novamente exportados para planilha eletrônica e somados para organizar uma base com dados anuais. Foram calculadas as médias anuais de precipitação pluvial do período e o total de chuva de cada ano do período de estudo. Estes cálculos possibilitaram a espacialização dos dados a partir do software de informação geográfica ArcGIS versão 10.3. ${ }^{\circledR}$.

A espacialização dos dados se fez pela inserção da tabela de atributos (coordenadas e dados pluviométricos) das estações pluviométricas para dentro do software ArcGIS e da base cartográfica em formato shapefile do Instituto Brasileiro de Geografia e Estatística (IBGE).

Dentro do ambiente SIG, utilizou-se o método de krigagem para a interpolação dos dados. Carvalho e Assad (2005) afirmaram que este é o método ideal para a construção de isoietas, quando compararam métodos de interpolação no estudo da precipitação pluviométrica do estado de São Paulo. Assad et al. (2003) compararam métodos de espacialização de índices agrometeorológicos e destacaram as vantagens da krigagem por indicação em relação a métodos determinísticos.

No presente estudo, foi utilizada a krigagem com o modelo de semivariograma exponencial para caracterizar a distribuição da precipitação pluvial na RMC. No software essa técnica é realizada pela extensão Spatial Analyst Tools através da aba Interpolation e ferramenta kriging. Essa técnica foi usada na elaboração dos mapas individuais (ano a ano) e do mapa geral.

\section{Resultados}




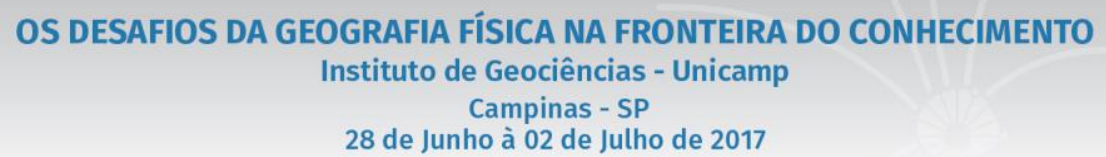

As correções dos dados pluviométricos por meio da sub-rotina prefann (Precipitation Forescating with Artificial Neural Network and others) foram consideradas aceitáveis, visto que os dados corrigidos foram comparados aos dados de estações próximas e as diferenças entre os dados estimados e os dados reais (de postos pluviométricos vizinhos) apresentaram-se com diferença ínfima. Cabe ressaltar que a precisão do método é desconhecida, por serem realizados cálculos nas camadas "escondidas", sendo possivelmente baixa, tendo em vista a alta variabilidade inerente à precipitação pluvial.

A organização dos dados diários em dados mensais possibilitou o cálculo da média e do coeficiente de variação do período, e os resultados podem ser visualizados na Tabela 1.

Tabela 1 -Estações pluviométricas e resultados da média e coeficiente de variação de 1976 a 2012

\begin{tabular}{lccccccc}
\hline Código & Nome da estação & Município & Latitude & Longitude & Altitude & $\begin{array}{c}\text { Média (1976 a } \\
\text { 2012) }\end{array}$ & $\begin{array}{c}\text { Coeficiente } \\
\text { de } \\
\text { Variação }\end{array}$ \\
\hline $\mathbf{2 2 4 6 0 2 0}$ & Fazenda Chapadão & Amparo & $-22,62$ & $-46,85$ & 760 & 1531,3 & $33 \%$ \\
$\mathbf{2 2 4 6 0 2 8}$ & Pedreira & Pedreira & $-22,75$ & $-46,93$ & 590 & 1506,5 & $18 \%$ \\
$\mathbf{2 2 4 6 0 3 4}$ & Morungaba & Morungaba & $-22,88$ & $-46,78$ & 750 & 1640,4 & $20 \%$ \\
$\mathbf{2 2 4 6 0 3 8}$ & Itatiba & Itatiba & $-22,98$ & $-46,82$ & 690 & 1506,1 & $19 \%$ \\
$\mathbf{2 2 4 7 0 2 8}$ & Fazenda Holambra & Jaguariúna & $-22,63$ & $-47,05$ & 600 & 1394,1 & $19 \%$ \\
$\mathbf{2 2 4 7 0 4 1}$ & Fazenda Monte & Campinas & $-22,783$ & $-47,03$ & 600 & 1490,8 & $18 \%$ \\
& D'este & & & & & & 1,8 \\
$\mathbf{2 2 4 7 0 4 2}$ & Barão Geraldo & Campinas & $-22,83$ & $-47,06$ & 630 & 1551,2 & $22 \%$ \\
$\mathbf{2 2 4 7 0 4 6}$ & Campinas - IA & Campinas & $-22,88$ & $-47,83$ & 710 & 1471,2 & $17 \%$ \\
$\mathbf{2 2 4 7 0 5 0}$ & Bairro Pavioli & Monte Mor & $-22,933$ & $-47,25$ & 610 & 1356,5 & $24 \%$ \\
$\mathbf{2 2 4 7 0 5 8}$ & Monte Mor & Monte Mor & $-22,95$ & $-47,296$ & 560 & 1343,2 & $19 \%$ \\
$\mathbf{2 2 4 7 0 7 5}$ & UHE Americana & Americana & $-22,69$ & $-47,55$ & 521 & 1418,6 & $18 \%$ \\
& Jusante & Artur & $-22,56$ & $-47,16$ & 640 & 1382,2 & $18 \%$ \\
\hline $\mathbf{2 2 4 7 1 0 0}$ & Artur Nogueira & Nogueira & & & & & \\
\hline
\end{tabular}

Conforme a tabela, a maior média de precipitação ocorre no município de Morungaba (1640,4 mm) e a menor ocorre em Monte Mor (1343,2 mm). A precipitação é relativamente variável na RMC, visto que o coeficiente de variação (que é uma medida de variabilidade em torno da média) oscila entre 17 e $33 \%$. A interpolação espacial dos dados por meio do método da krigagem também apresentou resultados satisfatórios nas análises da distribuição da precipitação pluvial na RMC.

Os resultados da espacialização da precipitação pluvial permitem a visualização gráfica dos resultados. Os maiores valores médios de precipitação foram encontrados na região Leste da RMC, nos municípios de Campinas, Pedreira, Itatiba e Morungaba. Os menores valores foram encontrados no extremo Norte (Engenheiro Coelho e Artur Nogueira) e Sudoeste (Monte Mor e Indaiatuba). A Figura 3 refere-se a pluviosidade na RMC, de 1976 a 2012. 


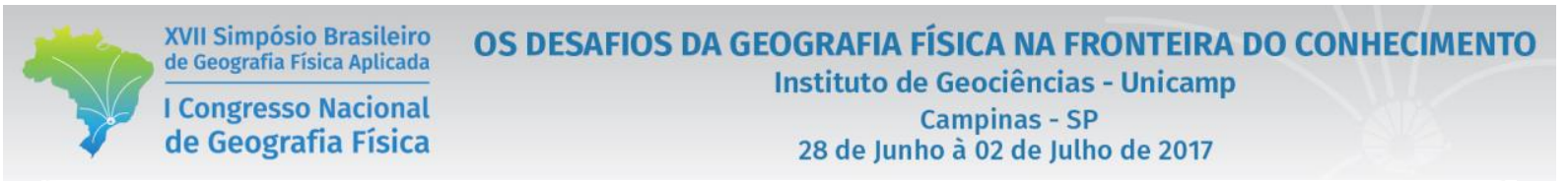

\section{PLUVIOSIDADE (MM) NA REGIÃO METROPOLITANA DE CAMPINAS NO PERIODO DE 1976 a 2012}

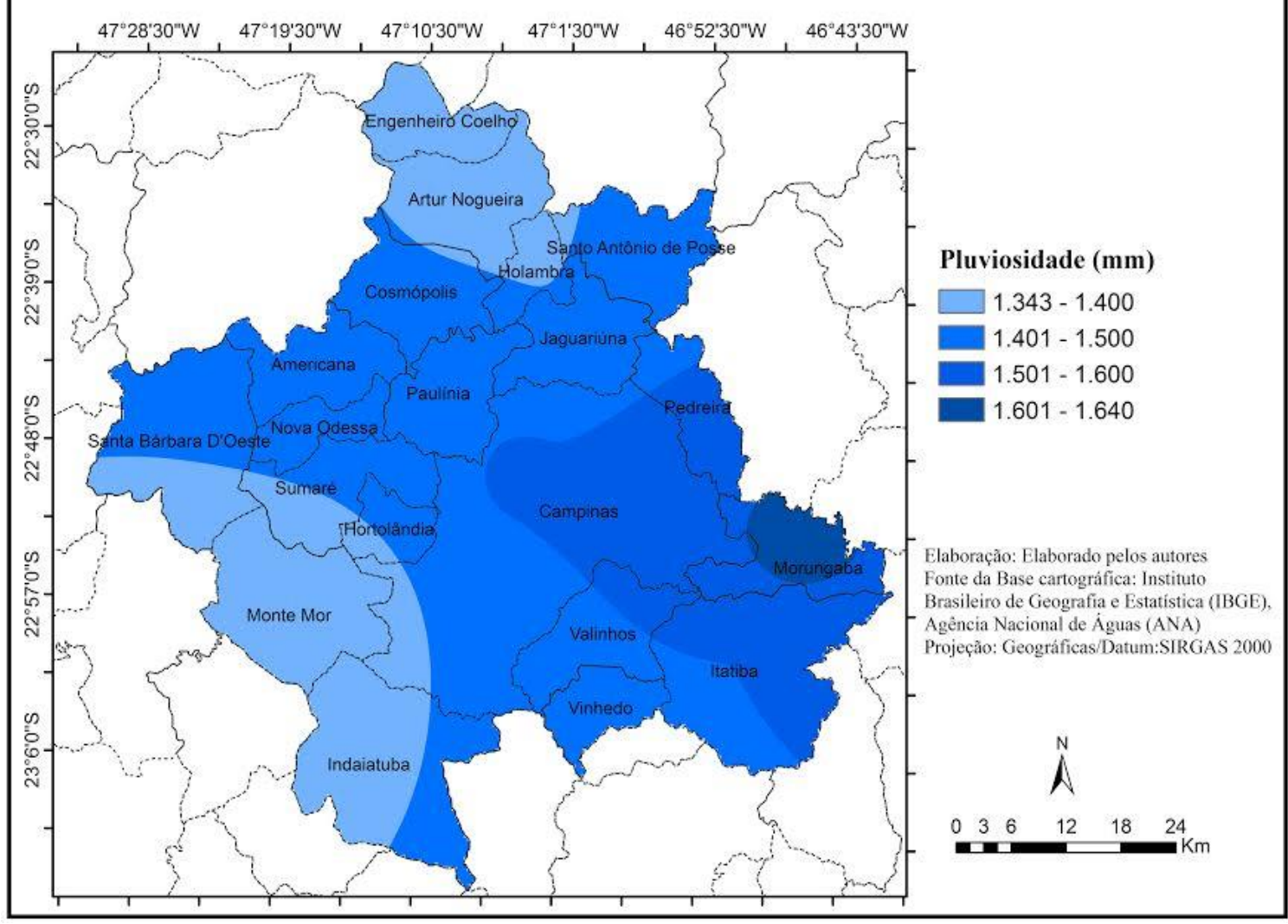

Figura 3 - Variabilidade da precipitação pluvial na Região Metropolitana de Campinas entre 1976 e 2012.

Dos 37 anos estudados, destacaram-se os anos 1976, 1982, 1983, 1986, 1987, 1995, 1996 e 2009, com totais anuais que ultrapassaram $2.200 \mathrm{~mm}$. Os resultados confirmam a interferência do fenômeno El Niño - Oscilação Sul (ENOS) (fase quente) sobre a precipitação pluvial do estado de São Paulo, mais especificamente sobre a RMC, tendo em vista que os anos com maiores valores totais anuais de chuva foram anos de ocorrência do fenômeno ENOS fase quente, conforme Figura 4. 

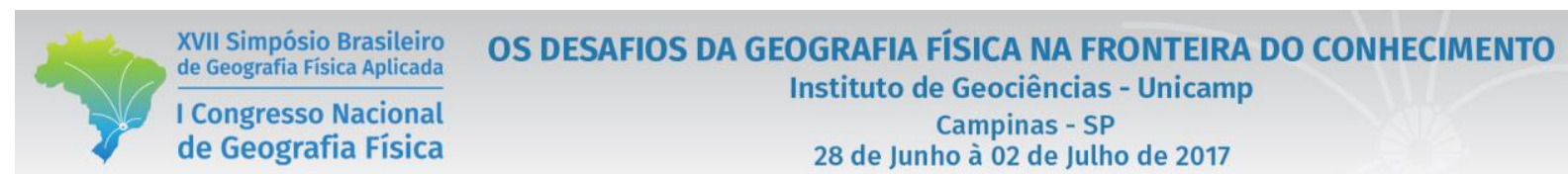

\begin{tabular}{|c|c|}
\hline $1972-1973$ & $1976-1977$ \\
\hline $1977-1978$ & $1979-1980$ \\
\hline $1982-1983$ & $1986-1988$ \\
\hline $1990-1993$ & $1994-1995$ \\
\hline $1997-1998$ & $2002-2003$ \\
\hline $2004-2005$ & $2006-2007$ \\
\hline $2009-2010$ & - \\
\hline Legenda: & Moderada \\
\hline
\end{tabular}

Figura 4 - Ocorrência de El Niño. (CPTEC, 2017).

Adaptado pelos autores.

Os resultados obtidos assemelham-se aos encontrados por Vicente (2005), que estudou eventos extremos na Região Metropolitana de Campinas de 1959/60 a 1998/99. O autor obteve que os maiores valores de precipitação pluvial ocorrem nos municípios de Campinas, Pedreira, Itatiba e Morungaba (região Leste da RMC). No mesmo trabalho, o autor confirma a influência da atuação do fenômeno El Niño (fase quente) e mostra que os anos 1982/83 foram os mais chuvosos.

A Figura 5 refere-se a espacialização do total de precipitação pluvial de cada ano do período de estudo. Percebe-se que os anos 1982 e 1983 (E1 Niño forte) são os mais expressivos em relação ao total de chuva, possuindo os maiores valores. Nestes anos, o total de precipitação pluvial na porção chuvosa da RMC (leste) oscila entre $2.601 \mathrm{e} 2.761 \mathrm{~mm}$. 
XVII Simpósio Brasileiro de Geografia Fisica Aplicada

I Congresso Nacional de Geografia Física
OS DESAFIOS DA GEOGRAFIA FÍSICA NA FRONTEIRA DO CONHECIMENTO Instituto de Geociências - Unicamp

Campinas - SP

28 de Junho à 02 de Julho de 2017

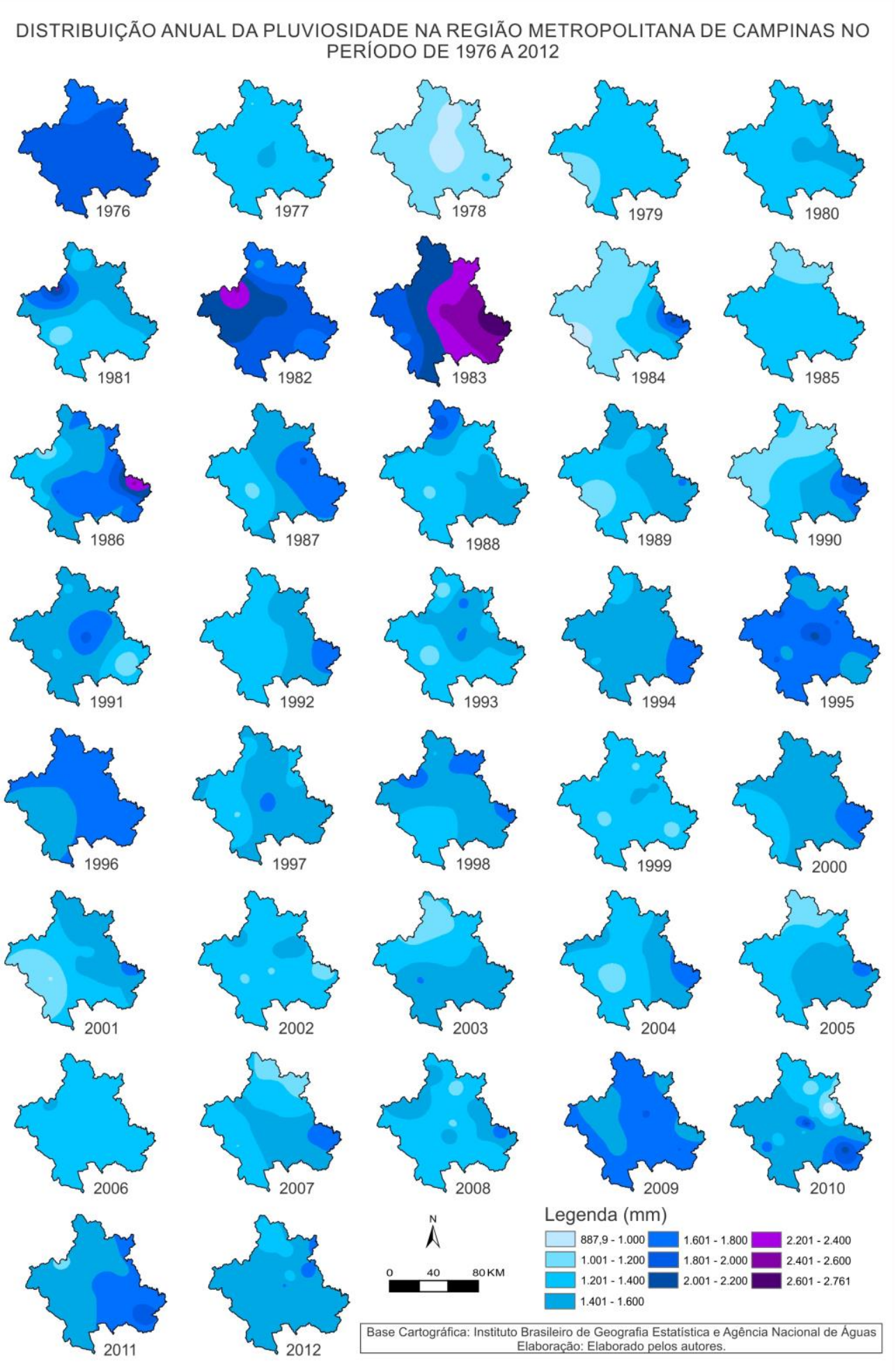

Figura 5 - Variabilidade de precipitação pluvial na Região Metropolitana de Campinas no período 1976 a 2012. 


\section{Conclusão}

As correções dos dados pluviométricos por meio da sub-rotina prefann e a interpolação espacial por meio do método de krigagem apresentaram resultados satisfatórios para as análises da distribuição da precipitação pluvial na RMC.

Os resultados revelaram que a média de precipitação pluvial do período de 37 anos (1976 - 2012) oscila entre 1.343 e $1.640 \mathrm{~mm}$. Em relação aos totais anuais, percebeu-se a influência da atuação do El Niño Oscilação Sul - fase quente, destacando-se o ano de 1982/83 como o ano com maiores totais, com a presença de um evento ENOS de intensidade forte.

Entender a dinâmica espaço-temporal da chuva na Região Metropolitana de Campinas é muito importante nas mais diversas áreas do conhecimento, contribuindo com um banco de dados para futuras análises interdisciplinares, principalmente no que tange aos estudos hidrológicos e de desastres naturais relacionados ao excesso de precipitação, que são comuns nesta região.

\section{Bibliografia}

ADAMS D.K, SOUZA E.P, COSTA A.A. Convecção úmida na Amazônia: implicações para modelagem numérica. Revista Brasileira de Meteorologia, v.24, n.2, p. 168-178, 2009.

ANA - AGÊNCIA NACIONAL DAS ÁGUAS. Disponível em: <http://hidroweb.ana.gov.br>. Acesso em: $14 / 12 / 2016$

ASSAD, E. D. et al. Avaliação de métodos geoestatísticos na espacialização de índices agrometeorológicos para definir riscos climáticos. Pesquisa Agropecuária Brasileira, v.38, n.2, p.161-171, 2003.

CARVALHO, J. R. P.; ASSAD, E. D. Análise espacial da precipitação pluviométrica no estado de São Paulo: Comparação de métodos de interpolação. Engenharia Agrícola, v.25, n.2, p.377-384, 2005.

CASTRO, F. S. et al. Avaliação do desempenho dos diferentes métodos de interpoladores para parâmetros do balanço hídrico climatológico. Revista Brasileira de Engenharia Agrícola e Ambiental, 14(8), 871880. https://dx.doi.org/10.1590/S1415-43662010000800012. 2010.

EMBRAPA. Projeto GeoAtlas. Centro Nacional de Pesquisa de Monitoramento por Satélite - CNPM. Disponível em: <https://www.cnpm.embrapa.br/projetos/geoatlas/index.html>. Acesso em: 10/02/2017.

HAYKIN, S. O. Neural networks and learning machines ( $3^{a}$ edição). Upper Saddle River, Nova Jersey: Prentice Hall, 2008.

IBGE. Censo Demográfico 2010. Instituto Brasileiro de Geografia e Estatística. Disponível em: < http://censo2010.ibge.gov.br/>. Acesso em 14/03/2017.

MELLO, C.R.; VIOLA,M.R.; CURI,N.; SILVA, A.M. Distribuição espacial da precipitação e da erosividade da chuva mensal e anual no Estado do Espírito Santo.Revista Brasileira de Ciência do Solo, vol.36, n.6, p.1878-1891, 2012. 
MORAES, C.M.; PEREIRA, G.; CARDOZO, F. S. Avaliação da precipitação e sua influência sobre as áreas inundadas no Pantanal. XVI Simpósio Brasileiro de Sensoriamento Remoto, 2013, Foz do Iguaçu. Anais... Foz do Iguaçu: SBSR 2013. p. 7216 - 7224.

POVOA, L.V. Prefann: Precipitation forecasting with Artificial Neural Network and others. Pacote do R. Versão 0.0.1. Disponível em: <https:/github.com/lucasvenez/prefann>. Acesso em 02/12/2016.

SILVA, K.R.; CECÍLIO, R.A.; XAVIER, A.C.; PEZZOPANE, J.R.M.; GARCIA, G.O. Interpolação Espacial da Precipitação no Estado do Espírito Santo. Floresta e Ambiente, v.18, n.4, p.417-427, 2011 a.

SILVA, S.A.; LIMA, J.S.; BOTTEGA, E.L. Variabilidade espacial da precipitação pluviométrica para o Estado do Espírito Santo utilizando métodos multivariados. Revista Brasileira de Ciência Agrária, Recife, v.6, n.4, p.703709, $2011 b$.

SOUZA, J.O.P.; ALMEIDA, J.D.M.; CORREA. A.C. Caracterização e espacialização da precipitação em bacia hidrográfica com relevo complexo: Sertão Central Pernambucano - Bacia do Riacho do Saco. Revista de Geografia (UFPE), v.32, n.2, 2105, p.106 - 126.

TEEGAVARAPU, R. S. V.; CHANDRAMOULI, V. Improved weighting methods, deterministic and stochastic data-driven models for estimation of missing precipitation records. Journal of Hydrology, v. 312, p. 191-206, 2005.

VICENTE, A. K. Eventos Extremos De Precipitação Na Região Metropolitana De Campinas. Dissertação de Mestrado. Universidade Estadual de Campinas. Campinas - SP, 2005. 